\title{
DO THE LATEST SCANNING ELECTRON MICROSCOPES WITH A VARIETY OF ANALYTICAL AND IMAGING TECHNIQUES PROVIDE US WITH REALISTIC IMAGES AND COMPOSITIONS?
}

\author{
ALI NAJNOVEJŠI SEM-MIKROSKOPI, OPREMLJENI Z \\ RAZLIČNIMI ANALITSKIMI TEHNIKAMI, PRIKAZUJEJO \\ REALNE SLIKE IN SESTAVE DEJANSKIH VZORCEV?
}

\author{
Črtomir Donik \\ Institute of Metals and Technology, Lepi pot 11, 1000 Ljubljana, Slovenia \\ Prejem rokopisa - received: 2019-11-04; sprejem za objavo - accepted for publication: 2019-11-14
}

doi: $10.17222 / \mathrm{mit} .2019 .269$

\begin{abstract}
The scanning electron microscope (SEM) has become a must-have for any research institution, university, or industry involved in material production, treatment, processing, research or even distribution. The SEM has evolved into probably the most common analytical tool in the materials research community, with its imaging, elemental analytics, phase analyses, local micro-stress analyses, in-situ cross-section preparation, lamella preparation for TEM, etc. Since the number of SEMs has drastically increased, due to its availability and its wide range of uses, increasing numbers of poorly trained SEM operators are involved in materials research and development. The resulting problem is that all analytical instruments always show "something" and the operator must know the limitations of the technique. The skilled and properly trained operator understands the physics behind the SEM and its associated analytical techniques, such as EDS, WDS, SIMS, EBSD, BEI, and ECCI.

Keywords: SEM, EDS, SEM imaging, FIB SEM, BSD
\end{abstract}

Vrstični elektronski mikroskop (SEM) je postal nujen v vseh raziskovalnih organizacijah, univerzah in v podjetjih, kjer se ukvarjajo s proizvodnjo, obdelavo, predelavo, raziskavami ali celo zgolj distribucijo materiala. SEM se razvija v verjetno najbolj uporabljano orodje za raziskovanje materialov s slikanjem, elementno analizo, faznimi analizami, lokalnimi mikroanalizami, kot tudi za pripravo in-situ preseka ter za pripravo lamel za TEM itd. Trenutno se s številom SEM-aparatur, ki se drastično viša. zaradi razpoložljivosti in široke uporabe na področju raziskav in razvoja, ukvarja vedno več mikroskopistov, ki pa so pomanjkljivo usposobljeni. Težava, ki izhaja iz omenjene kombinacije je, da vsi analitski mikroskopi vedno pokažejo nekaj, naj bo to neka številka ali neka slika, mikroskopist pa mora vedeti in tudi poznati omejitve uporabljenih tehnik. Dovolj usposobljen mikroskopist razume fiziko SEM-a in njegovih analitskih tehnik kot so: EDS, WDS, SIMS, EBSD, BEI, ECCI itd.

Ključne besede: SEM, EDS, SEM, FIB SEM, BSD

\section{INTRODUCTION}

With increased demands in materials research at the submicron-to-nano level, almost all scanning electron microscopes (SEMs) are equipped with an energy-dispersive spectroscopy (EDS) detector. With the increased number of EDS detectors, its larger detector-window size, the resulting increased scanning speed, accuracy and with the use of multiple EDS detectors on a single SEM, EDS is rapidly moving from being a purely analytical spectroscopy technique to becoming a good imaging technique, but with certain physical limi tations. ${ }^{1-4}$ The recent improvements in EDS performance with a silicon drift detector (SDD) enable accuracy and precision almost equivalent to a high-resolution wavelength-dispersive spectrometer (WDS) employed on an electron-probe microanalyzer platform. ${ }^{2,5}$ The SDD-EDS output, resolution, and stability provide operating conditions for the measurement of high-count spectra that form the basis for peak-fitting procedures that

*Corresponding author's e-mail:

crtomir.donik@imt.si (Črtomir Donik) recover the characteristic peak intensities even for elemental combinations where a large peak overlap occurs. As the beam scans over the sample surface and an X-ray spectrum is recorded for every pixel, an EDS map is built up and can qualitatively indicate the presence of different elements and with some data postprocessing even the phases of the sample. If the spectra acquired during the EDS mapping are live-time corrected, they can be processed and quantified like any other spectrum. This enables the reconstruction and quantification of spectra from features of interest in maps. ${ }^{4,6-8}$

Another SEM imaging technique directly correlated to the chemistry of the surface is the backscatteredelectron image (BSD). In theory, BSD images display compositional contrast that results from the different atomic numbers $(\mathrm{Z})$ of the elements and their distribution. However, as both the backscattered-electron image and the EDS map are spatially registered, it is possible to use image processing of the electron image to identify features of interest and then extract the compositional information from the maps automatically. This process 
shows how a BSD image clearly distinguishes the phases in the sample. By thresholding the BSD image we can identify features of interest; in this case different phases in the sample. ${ }^{9-13}$

Focused-ion beam (FIB) instruments are typically paired with an SEM column in a combined FIB SEM machine. The FIB has been extensively used to prepare specimens for many analytical techniques. Auger electron spectroscopy (AES), X-ray electron spectroscopy (XPS), secondary-ion mass spectroscopy (SIMS), and EDS are the most common techniques for surface elemental analysis and EDS is probably the easiest to add to a FIB SEM. Knowledge of the penetration range of the electron beam coupled with material removal using the ion beam ( $\mathrm{Ga}, \mathrm{Xe}, \mathrm{Be}$, etc.) can provide significant information about the specimen. Earlier work showed that the removal of material behind the region of interest could improve the quality of the EDS image. ${ }^{14-17}$

Figure 1 shows how the lines within the interaction volume delineate the regions where the effect indicated predominates. For example, only X-rays emerge from the sample from the deeper parts of the sample and the depth of this interaction volume can be calculated and simulated with a Monte Carlo simulation.

The Monte Carlo method (Figure 2) is an effective tool for examining the basis, the reliability and the limitations of quantification procedures. In the context of materials analysis, Monte Carlo simulations can be important for analysing the electron paths and x-ray generation under unconventional measurement conditions or in samples with a complex geometry. The depth of the electron-interaction volume is directly correlated with the energy of the electron source and the material. As the image indicates, the Auger electrons emerge from a very thin region of the sample surface (maximum depth $\approx 5 \mathrm{~nm}$ ), meaning it is a surface technique. The outline of the volume for the characteristic x-ray production is defined by the case where the energy of an electron, $E$, is just sufficient to produce x-rays requiring energy, $E_{\mathrm{c}} \cdot{ }^{19-21}$

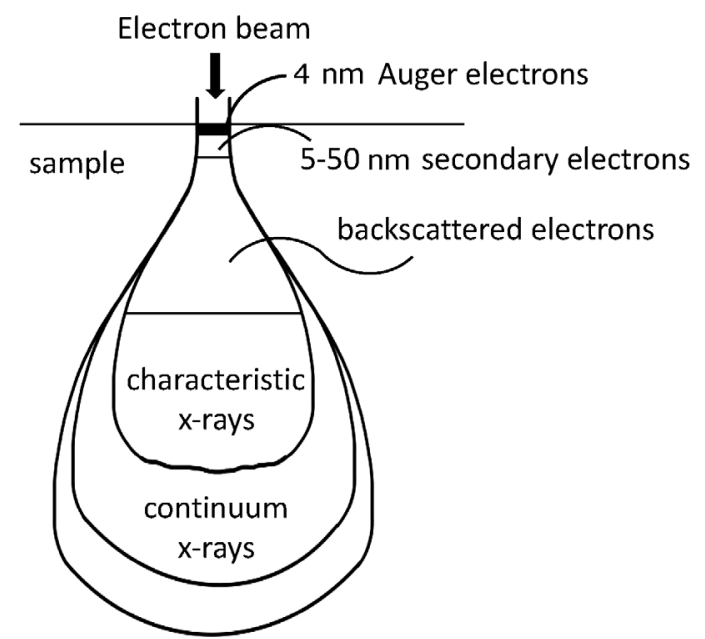

Figure 1: Schematic illustration of the interaction volumes for various electron-specimen interactions

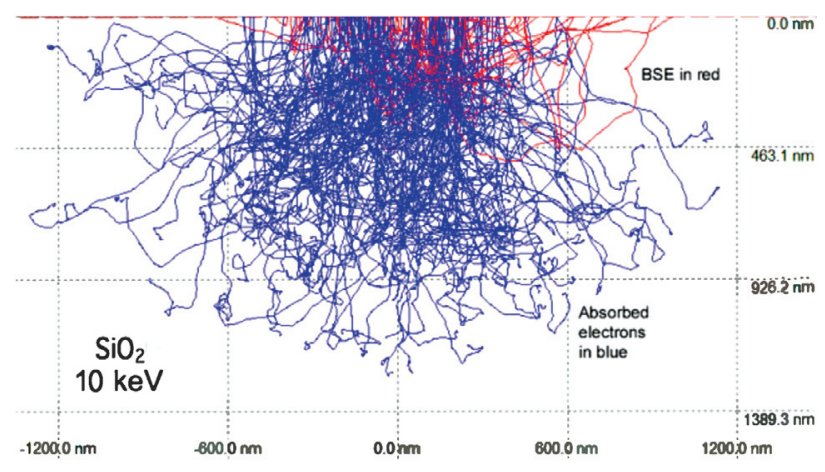

Figure 2: Monte Carlo simulation of the electron paths in a real sample. This simulation is for $10-\mathrm{kV}$ electrons in quartz $\left(\mathrm{SiO}_{2}\right)$. The paths of the backscattered electrons are red, while the absorbed electrons are blue. This model was run using Casino software. ${ }^{18}$

To overcome the energy-measurement dilemma, in the 1950s Castaing 22 developed the " $k$-ratio" protocol based on measuring the characteristic x-ray intensity, $I$, for the same element in the unknown and in a standard of known composition:

$$
k=I_{\text {unknown }} / I_{\text {standard }}
$$

The characteristic $\mathrm{x}$-ray peak intensity is corrected for the background and measured under identical conditions of the beam energy, the known dose, and the detector efficiency for both the unknown sample and the standard. By measuring the same peak under identical conditions, the same efficiency value effectively appears in both the numerator and the denominator of (Equation 1 ) as a multiplier of the intensity, and thus the efficiency quantitatively cancels in the $k$-ratio. Castaing further described the basis for the physical calculations that are necessary to convert the set of k-ratios into mass concentrations, with the following Equation (2):

$$
C_{\mathrm{i}} / C_{\text {std }}=k_{\mathrm{i}} Z A F C
$$

where $C_{\text {std }}$ is the mass concentration of the element of interest in the standard; $Z, A, F$, and $c$ are the "matrixcorrection factors" that calculate the compositionally dependent inter-element effects of electron scattering and energy loss $(Z)$, x-ray self-absorption within the specimen $(A)$, and secondary $\mathrm{x}$-ray emission following the self-absorption of the electron-excited characteristic $(F)$ and continuum $(c)$ x-rays. Importantly, for the Castaing standard-based k-ratio method, the standards do not require a closely matched composition of the unknown sample, which is an enormous advantage when dealing with complicated multi-element unknowns. The depth of the electron penetration generally ranges from $1 \mu \mathrm{m}$ to $5 \mu \mathrm{m}$ when the beam is incident perpendicular to the sample. The average depth (in $\mu \mathrm{m}$ ), $x$, can be calculated by P. J. Potts ${ }^{23}$ (Equation 3 ):

$$
x=0.1 E_{\mathrm{o}}^{1.5} \rho^{-1}
$$

where, $E_{\mathrm{o}}$ is the accelerating voltage $(\mathrm{kV})$ and $\rho$ is the density of the analysed material $\left(\mathrm{g} / \mathrm{cm}^{3}\right)$. For example, bombarding a steel material with an average density of 


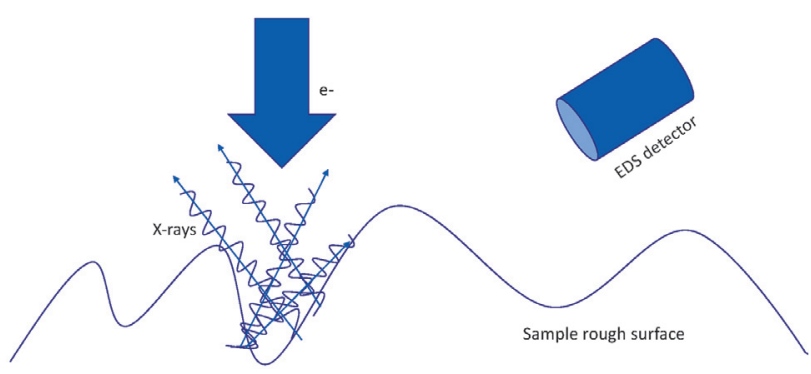

Figure 3: Schematic of $x$-ray scattering where a rough surface with peaks shadowing/preventing the $\mathrm{x}$-rays from reaching the EDS detector

$7.8 \mathrm{~g} / \mathrm{cm}^{3}$ (about the density for steels) with $E_{0}=15 \mathrm{kV}$, yields a depth $x=0.74 \mu \mathrm{m}$.

Accuracy of the EDS method:

- $\pm 1 \%$ for a polished bulk target, pure standards on site,

- $\pm 2 \%$ for a polished bulk target, standards collected on another SEM and then corrected for the geometry and settings of the present microscope "without standards",

- $\pm 5 \%$ for particles and rough surfaces "without standards.

Obviously, all of the mentioned constraints are necessary to understand the imitations of the EDS technique; however, the spatial resolution of the signal is often surprising to novices. The units of the spatial resolution are microns - not nanometres. Also, it is common to use intermediate $(15-20 \mathrm{keV})$ accelerating voltages to ensure the peaks we want to record. Of course, the size of the interaction volume increases with the accelerating voltage. EDS is not a surface-sensitive analytical technique. It does not need to magnify significantly in the SEM mode to reach the point where the pixel size on the specimen approaches this limit of the EDS-SEM image..$^{2,24-26}$

The aim of the current study is to show how important it is to know the background of the material you investigate and the physical limitation of the techniques you are using. The study is supported with real cases and a calculations background.

\section{EXPERIMENTAL PART}

Several different samples were analysed and further revised to show the importance of the correct interpretation of the results obtained by SEM analyses. Nanoparticles were rearranged across a TEM sample holder mesh, without any other preparation. The surfaces of the metallic samples were prepared by grinding down to 1200 grit and polishing down to $1 \mu \mathrm{m}$ with a diamond suspension.

The chemical composition of the different alloys was determined with an X-ray fluorescence (XRF) spectrometer (Thermo Scientific Niton XL3t GOLDD+), a carbon and a sulphur analyser (ELTRA CS-800). The chemical composition of the multi-walled carbon nanotubes (MWCNTs) doped with nanoparticles of $\mathrm{Al}_{2} \mathrm{O}_{3}$ was measured. The $\mathrm{Al}_{2} \mathrm{O}_{3}$ nanoparticles are necessary for the production of these MWCNTs. The chemical composition of a commercially pure (cp) $\mathrm{Ti}$ and a Ti6Al4V

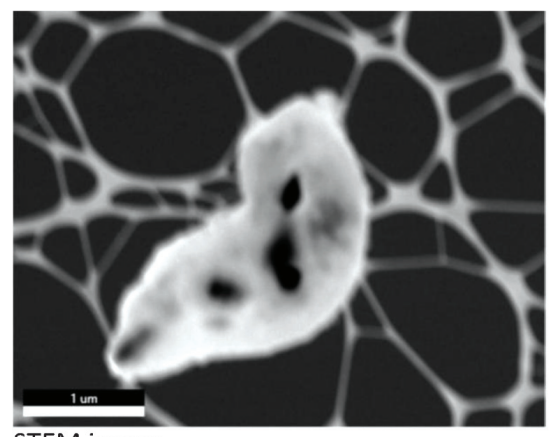

STEM image

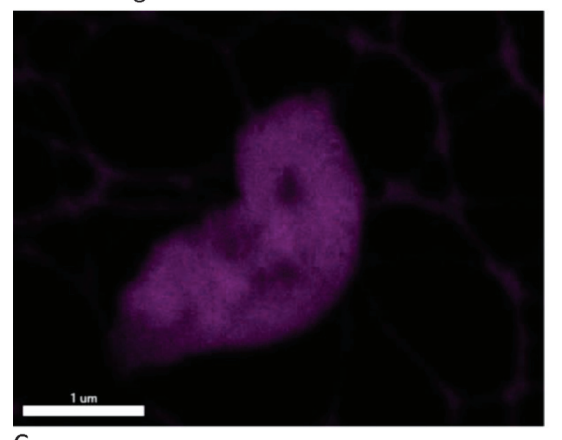

C

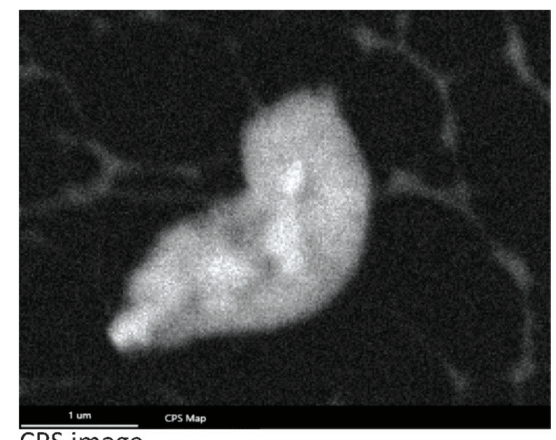

CPS image

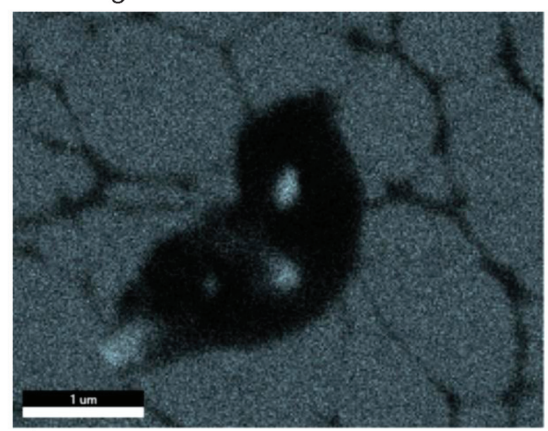

Al

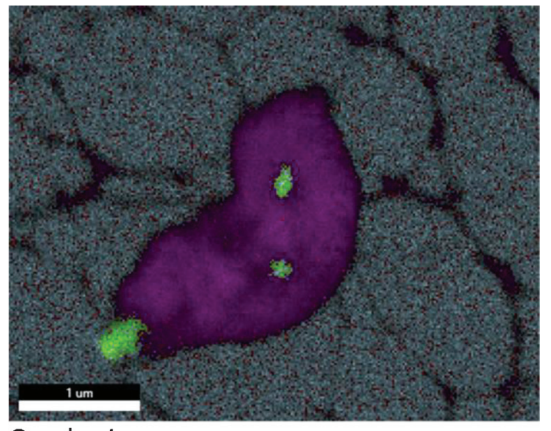

Overlay image

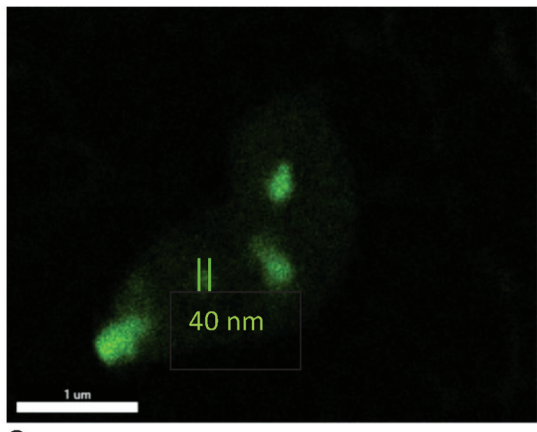

0

Figure 4: EDS mapping of carbon nanotubes with nano $\mathrm{Al}_{2} \mathrm{O}_{3}$ on a TEM polymer mesh analysed in STEM mode at a high accelerating voltage at higher magnifications (up to 100.000x) where less-than-50-nm particles can be observed and identified as Al and $\mathrm{O}$ (which corresponds accurately to $\left.\mathrm{Al}_{2} \mathrm{O}_{3}\right)$. 
alloy were $99.95 w / \%$ Ti and $6.05 w / \% \mathrm{Al}, 3.83 w / \% \mathrm{~V}$ and balance Ti, respectively. The composition of highspeed steel (HSS) of grade M1 is $0.83 w / \%$ C, $4.12 w / \%$ Cr, $7.5 w / \%$ Mo, $1.05 w / \% \mathrm{~V}$, balance Fe; the composition of Al with Ag particles IS $0.5 w / \% \mathrm{Ag}, 1.4 w / \%$ $\mathrm{Cu}, 0.12 w / \% \mathrm{Fe}, 2.3 w / \% \mathrm{Mg}, 5.5 w / \% \mathrm{Zn}$.

FIB SEM analyses were carried out using a ZEISS Crossbeam 550 with an EDAX EDS Octane Elite analyser and a Hikari Super EBSD Camera. For the EDS, EDS mapping and EBSD analyses we used EDAX $\mathrm{TEAM}^{\mathrm{TM}}$ to investigate the microstructure, morphology and EDS mappings of the surfaces.

\section{RESULTS AND DISCUSSION}

In the first presented case, Figure 4 shows a combination of the images of nanoparticles with carbon nanotubes in the scanning transmission electron microscopy (STEM) mode. The STEM detector is present inside the SEM with an accelerating voltage of $30 \mathrm{kV}$. The images in Figure 4 were observed in the transmission mode. The acceleration voltage is lower than in the TEM, but of course, high enough for the EDS measurements and the EDS mapping. Since the sample is thin enough, the characteristic x-rays (Figure 1) would, according to Equation $3\left(30 \mathrm{kV}, 3.95 \mathrm{~g} / \mathrm{cm}^{3}\right.$ for $\left.\mathrm{Al}_{2} \mathrm{O}_{3}\right)$, emerge from approximately $4.2 \mu \mathrm{m}$ deep within the sample. This would also mean that the EDS mapping would not reveal increased areas of $\mathrm{Al}$ and $\mathrm{O}$, but maybe just some smaller smear or a smudge of $\mathrm{Al}$ and $\mathrm{O}$ on the mapping of the carbon nanotubes. As observed from the images in Figure 4, a properly prepared TEM sample "can modify" the limitation and constraints of the EDS measurements. While the characteristic X-rays emerge just from the sample and not from the bulk below, the resolution for the EDS mapping is in the range of few tens of $\mathrm{nm}$. The limitation of "10,000× magnification" as the limit of the "normal EDS mapping" does not apply here and the microns of resolution in the EDS mapping is moved to a few tens of $\mathrm{nm}$, as observed above $\left(\mathrm{Al}_{2} \mathrm{O}_{3}\right.$ particle approx. 40-50 nm - Figure 4) and could also be lower with "perfect conditions" ( $\mathrm{Au}$ nanoparticles on $\mathrm{C}$ ), for instance. On the other hand, the present EDS mapping also reveals one of the problems in STEM mode - the signal of the surrounding holder (Al holder) is shown on the Al mapping. So, how could we distinguish the "real $\mathrm{Al}$ " and the "Al from the holder"? The answer is the counts per second (CPS) map, where the concentration of the signal is shown and so we can distinguish the difference between the $\mathrm{Al}$ from the holder and from the sample.

On the other hand, Figure 5 demonstrates the phenomenon described in Figure $\mathbf{3}$ with the roughness/ shadowing of the sample and the different escape paths of the x-rays. From the EDS mappings we can clearly observe the variation in the appearance of selected element maps. As we know from EDS spectra ${ }^{1,2,5}$, different elements have different characteristic X-ray energies. The interaction volume is defined by the energy
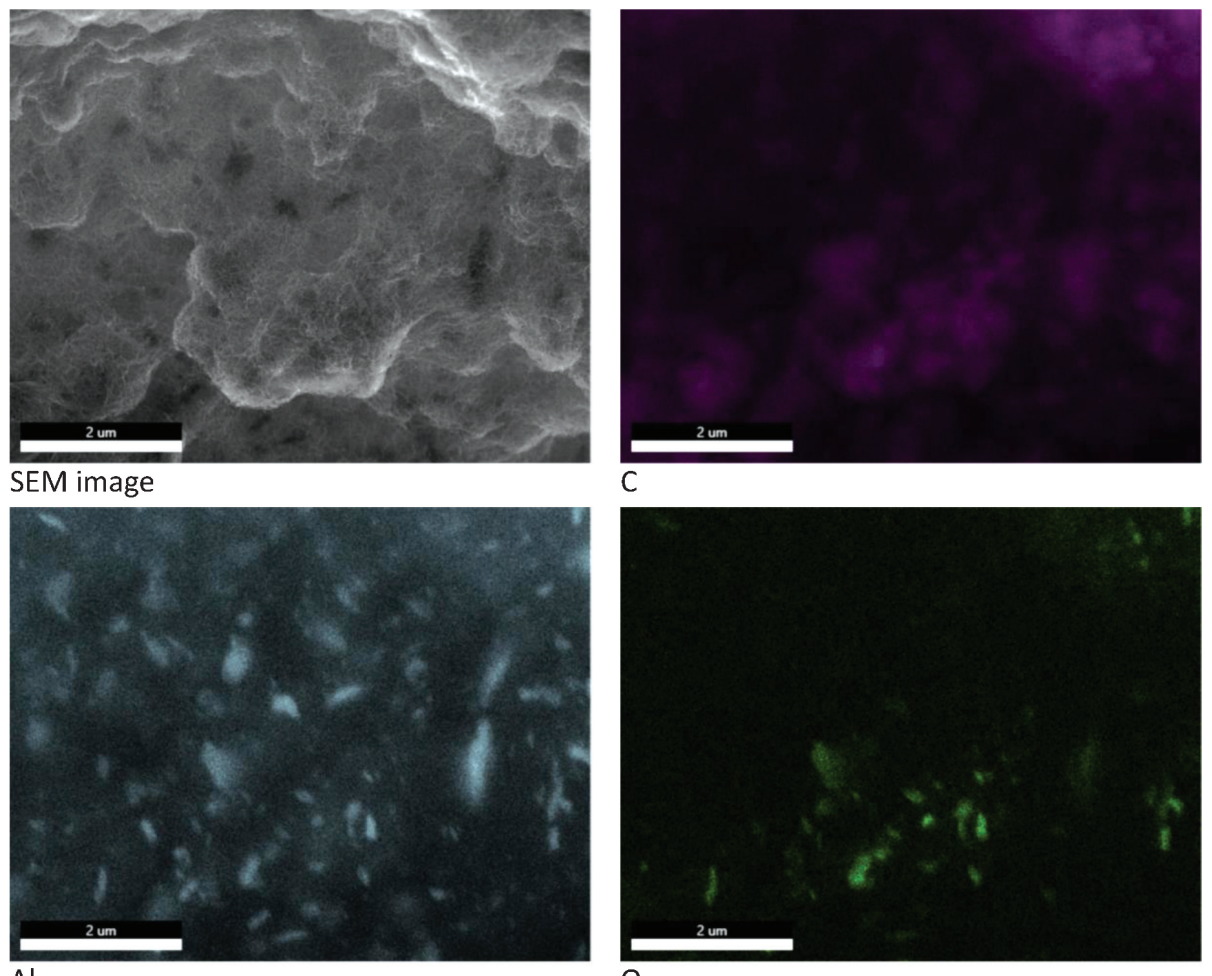

Al

$\mathrm{O}$

Figure 5: EDS mapping of carbon nanotubes with nano $\mathrm{Al}_{2} \mathrm{O}_{3}$ analysed in the normal SEM mode at a high accelerating voltage at higher magnifications, where a less-than-50-nm particle can be observed and identified as $\mathrm{Al}$ and $\mathrm{O}$ (which corresponds accurately to $\mathrm{Al}_{2} \mathrm{O}_{3}$ ) 
of the electron beam source. On the other hand, in the presented case, the source has, of course, the same energy for all the elements; however, the elemental distribution maps differ due to the shadowing. The difference is just in the characteristic X-ray energies involved in the EDS mappings $-\mathrm{C}$ at $K_{\alpha}=0.277 \mathrm{keV}$, O at $\mathrm{K}_{\alpha}=0.523 \mathrm{keV}$ and $\mathrm{Al}$ at $K_{\alpha}=1.486 \mathrm{keV}$. From these mappings we can see $\mathrm{Al}$, even in the regions where "no C" can be observed, even though the whole sample is CNTW. Even the SEM image does not clearly reveal the $\mathrm{Al}$ nanoparticles, since they are not on the top layer. The $\mathrm{Al}_{2} \mathrm{O}_{3}$ nanoparticles are below/in the middle of the carbon nanotubes, but the maps show just $\mathrm{Al}$ particles. A similar phenomenon can be observed with $\mathrm{O}$, since all the $\mathrm{Al}$ nanoparticles are in the form $\mathrm{Al}_{2} \mathrm{O}_{3}$, and so "no $\mathrm{Al}$ is without $\mathrm{O}$ ". However, in the image we can observe some areas that are shadowed towards the EDS detector and only $\mathrm{Al}$ is presented on the maps. The question is why does this occur? The answer is that the X-rays with higher energies (shorter wavelengths) (like $\mathrm{Al}$ ) penetrate through some thin layers of the nanotubes, even when they are shadowed towards the EDS detector. The X-rays with just slightly lower energies (longer wavelengths) $(O$ and $\mathrm{C}$ ) does not penetrate the shadowing. This should be kept in mind for an explanation of the non-polished samples, e.g., cracks, crevices, corrosion products, etc. The inclusions, oxides, precipitations, etc., have elements that differ in the X-ray energies and consequently in different penetration paths.

Figure 6 shows the mapping problems for the two similar materials combined. The studied combination is cp-Ti and the Ti6Al4V alloy, i.e., biomaterials. From the EDS maps, practically no difference can be observed in the mapping of Ti. This is to be expected, since the concentration of $\mathrm{Ti}$ is higher than $90 \mathrm{w} / \%$ in both materials. On the other hand, the mapping of $\mathrm{Al}$ shows an increased amount of $\mathrm{Al}$ in the part of Ti6Al4V, since the cp-Ti possesses no Al. In contrast, the amount of $\mathrm{V}$

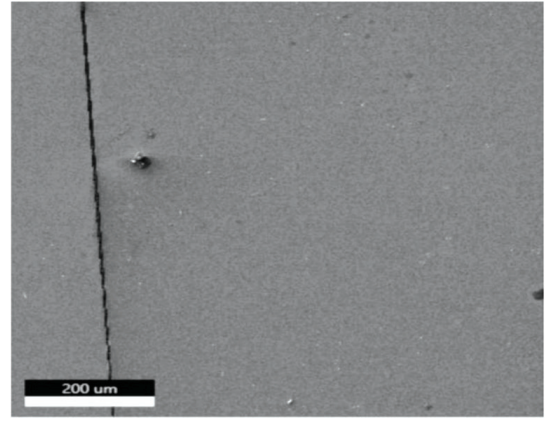

SEM image

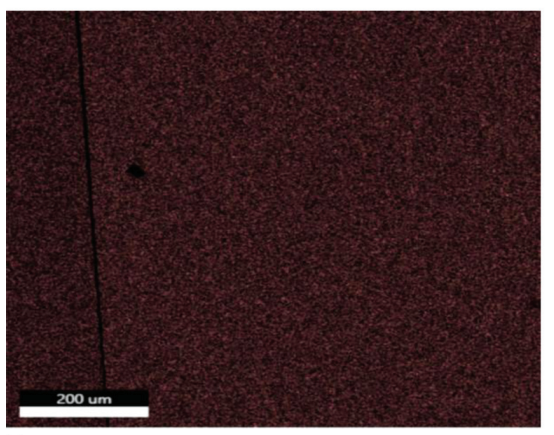

V

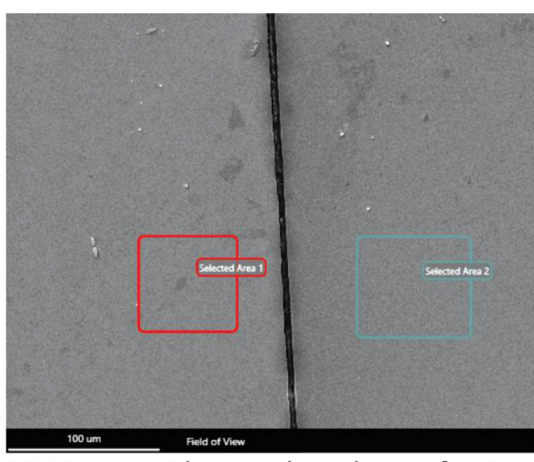

SEM image with two selected areas for EDS

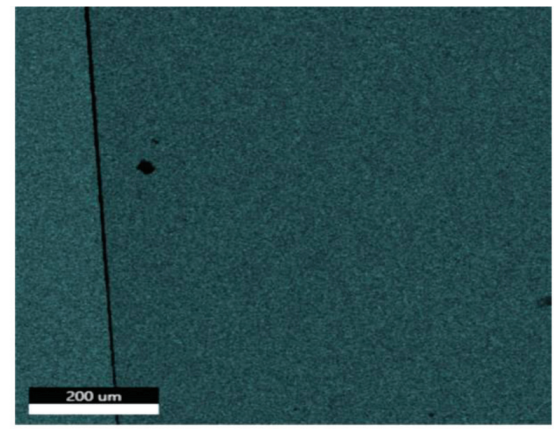

$\mathrm{Ti}$

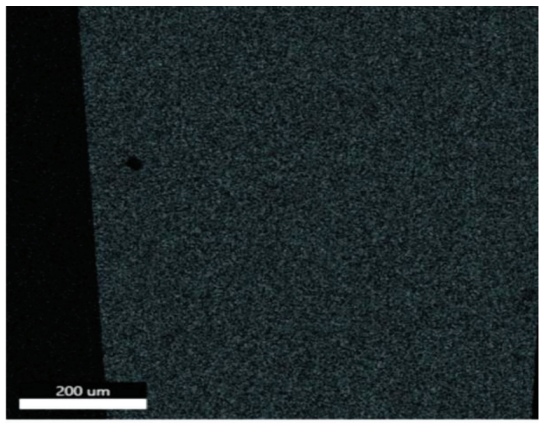

Al

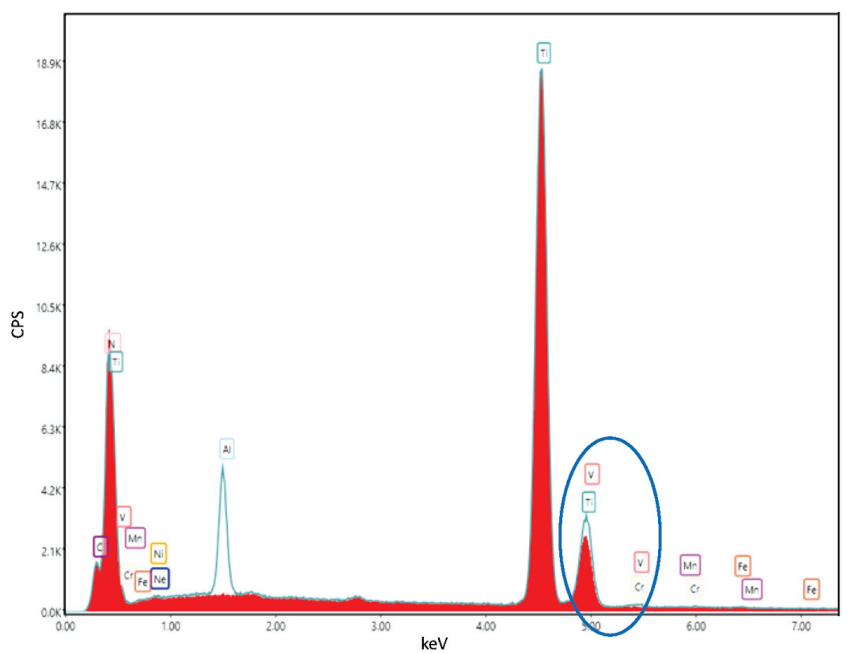

EDS spectra with marked area of $K_{\alpha 1}$ and $K_{\beta 1}$

Figure 6: EDS mapping and SEM image with selected areas for EDS area analyses of Ti and TiAlV alloy 


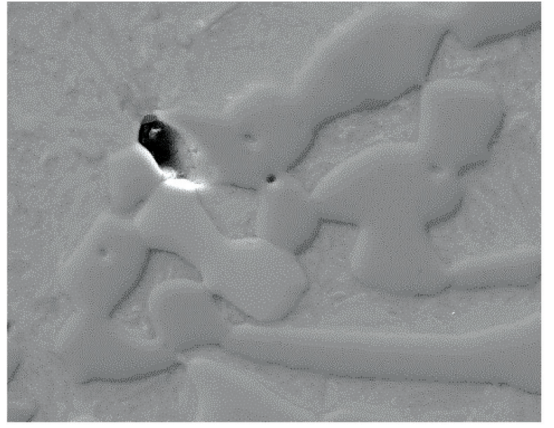

SE image

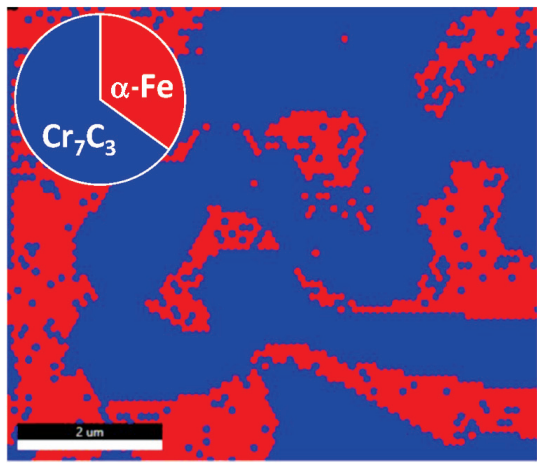

Phase image

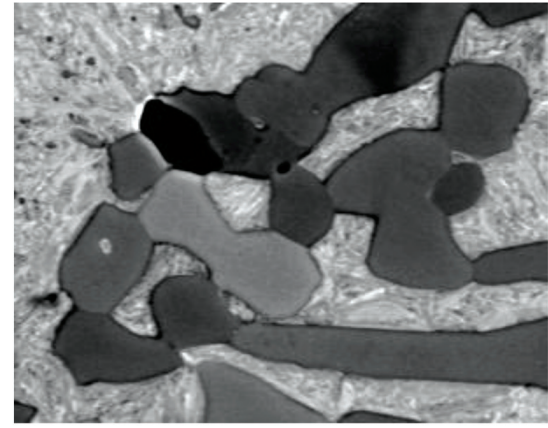

BSD image

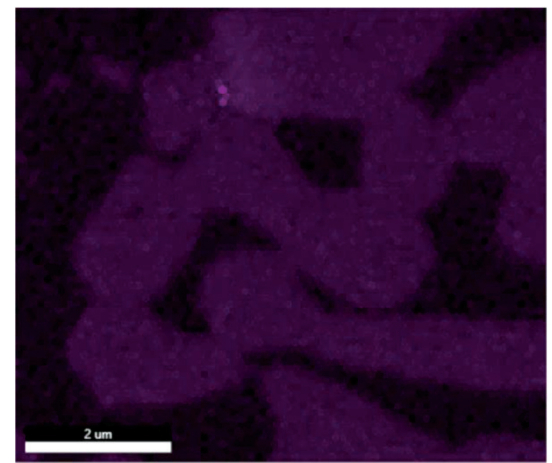

EDS mapping - $C$
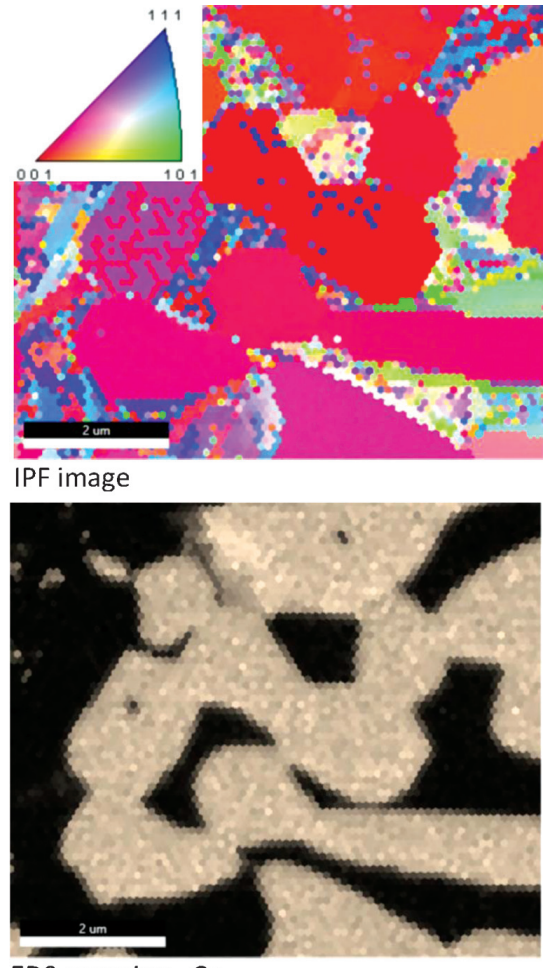

EDS mapping - $\mathrm{C}$

Figure 7: SE, BSD images with comparison to EBSD and EDS mapping analyses of small area of interest with $\mathrm{Cr}_{7} \mathrm{C}_{3}$ carbides in tool steel

seems to be very high and similar to the EDS map of Ti for both materials. The EDS mappings are correlated with the characteristic X-ray energies involved - Ti at $\mathrm{K}_{\alpha 1}=4.512 \mathrm{keV}, \mathrm{K}_{\beta 1}=4.933 \mathrm{keV} ; \mathrm{V}$ at $\mathrm{K}_{\alpha 1}=4.953 \mathrm{keV}$, $\mathrm{K}_{\beta 1}=5.428 \mathrm{keV}$ and $\mathrm{Al}$ at $\mathrm{K}_{\alpha 1}=1.486 \mathrm{keV}$. With Ti more than $90 \mathrm{w} / \%$ in the Ti6Al4V alloy, all the peaks are high and also the second $\mathrm{K}_{\beta 1}$ is just $0.02 \mathrm{keV}$ lower than the $\mathrm{K}_{\alpha 1}$ of $\mathrm{V}$. The mapping does not show the amount of $\mathrm{V}$ in the alloy, but the amount of $\mathrm{Ti}$ from the $\mathrm{K}_{\beta 1}$ peak instead. The other possibilities to overcome the issue could be the L peaks; however, they are even closer together and also some other peaks overlap at around $0.5 \mathrm{keV}$. The $\mathrm{K}_{\beta 1}$ peak of $\mathrm{V}$ could be used for the identification, analyses, and mapping, but the intensity is more than 10 times lower than the intensity of $\mathrm{K}_{\alpha 1}$ for $\mathrm{V}$, and a concentration of $\mathrm{V}$ lower than $4 w / \%$ could not be used. The last image of the presented EDS spectra for the selected areas shows the described problem and the ratios between the $\mathrm{K}_{\beta 1}$ peak of Ti and the $\mathrm{K}_{\alpha 1}$-peak of the $\mathrm{V}$ peaks around $5 \mathrm{keV}$, where the $\mathrm{K}_{\beta 1}$-peak of $\mathrm{V}$ is not even higher than the background.

Figure 7 reveals the combination of scanning electron (SE) and BSD images with different shades of grey on the BSD compared to the SE image. By definition ${ }^{19,27}$, BSD displays the compositional contrast that results from the different atomic numbers of the elements and their distribution. The higher is the $\mathrm{Z}$ number of the observed element, the darker is the area on the BSD image. In Figure 7 the grey shades of the BSD image vary from almost black to a very light grey. However, these grey shades are not connected to the different chemistry, but are connected to the crystallography of the same type of carbide $\left(\mathrm{Cr}_{7} \mathrm{C}_{3}\right)$, just with a different orientation. This phenomenon is known and it is applied with another technique - electron channelling contrast image (ECCI) ${ }^{28}$ ECCI is an imaging technique in scanning electron microscopy that is based on electron channelling applying a backscatter electron detector and it is used for the direct observation of lattice defects, for example, dislocations or stacking faults, close to the surface of bulk samples at high magnifications.

From the phase image in Figure 7, the carbides were confirmed as just $\mathrm{Cr}_{7} \mathrm{C}_{3},{ }^{29}$ and no other types of carbide were present, with the martensite matrix. The IPF image confirmed the different shading with a slight change of the orientation of the observed carbides. The last two images of Figure 7 confirmed the chemical composition of $\mathrm{Cr}$ and $\mathrm{C}$ for the spotted carbides.

In the described case it is clear that we should be very careful when only the grey shade differs in backscattered (BSD) image. It is possible that just the orientation/crystallography is changed and not also the chemical composition. Therefore, we should also be aware of this when automatic particle analyses are performed, since there the thresholds are defined only by the different shades of grey and like in the presented case, the results would not show the real features of the sample.

Figure 8 reveals the issue of sum peaks with $\mathrm{Al}$ and Ag. ${ }^{30,31}$ The sum peak of $\mathrm{Al}$ at the $\mathrm{K}_{\alpha 1}$ peak of $\mathrm{Al}$ 


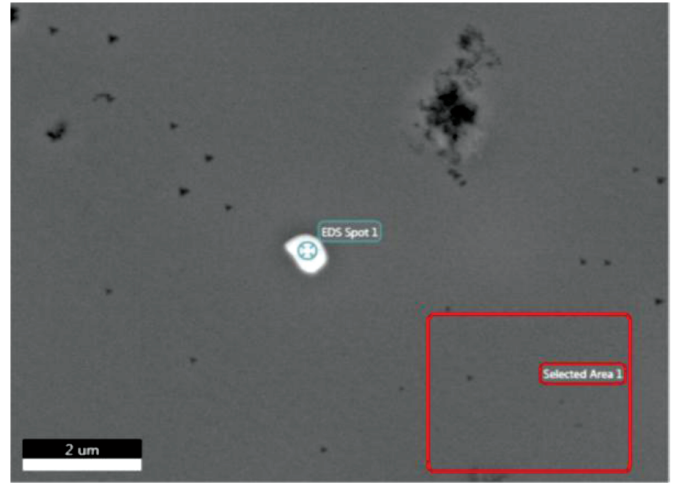

SEM image with EDS spots and areas

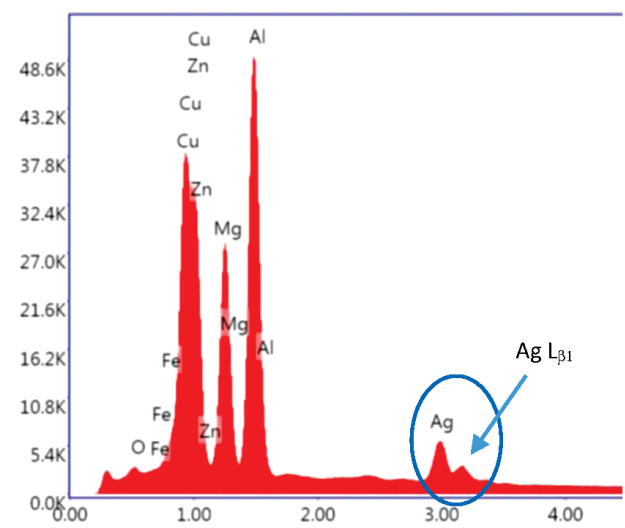

EDS spectrum - inclusion (Spot 1)
Table 1: EDS results (in w/\%)

\begin{tabular}{|c|c|c|}
\hline & $\begin{array}{c}\text { Spot } \\
1\end{array}$ & $\begin{array}{c}\text { Selected } \\
\text { area 1 }\end{array}$ \\
\hline $\mathrm{Mg} \mathrm{K}$ & 17.2 & 1.9 \\
\hline $\mathrm{Al} \mathrm{K}$ & 30.5 & 82.6 \\
\hline $\mathrm{Ag} \mathrm{L}$ & $\mathbf{8 . 2}$ & $\mathbf{1 2 . 5}$ \\
\hline $\mathrm{Cu} \mathrm{K}$ & 20 & 0.2 \\
\hline $\mathrm{Zn} \mathrm{K}$ & 23.9 & 2.7 \\
\hline
\end{tabular}

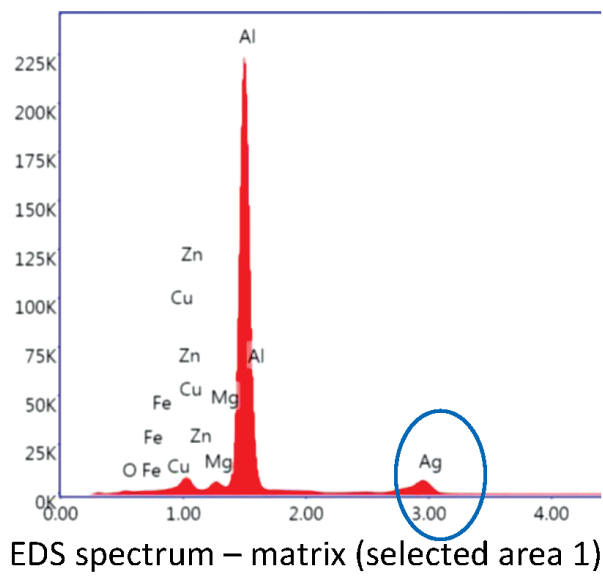

Figure 8: SE images with EDS analyses of small area of interest with $\mathrm{Al}$ and $\mathrm{Ag}$ overlapping

$\left(\mathrm{K}_{\alpha 1}=1.486 \mathrm{keV}\right)$ for a 2-times value is unfortunately where the $\mathrm{L}_{\alpha 1}$ of the $\mathrm{Ag}$ peak is $\left(\mathrm{L}_{\alpha 1}=2.938 \mathrm{keV}\right)$ positioned. This sum peak of $\mathrm{Al}$ is high enough since the concentration is high and overlaps the observed peak of $\mathrm{Ag}$. The problem exists while the automatic calculation of the software, even though the sum peaks should be excluded, is treated as combined and the concentration is summed together. The issue is with all the calculations of the $\mathrm{Ag}$, since $\mathrm{Ag}$ is not present in the $\mathrm{Al}$ alloy, it is just in the precipitates. The results show the concentration of $\mathrm{Ag}$ around $8 w / \%$, while in the matrix, where no $\mathrm{Ag}$ is diluted in the solid solution, the concentration of $\mathrm{Ag}$ is as high as $12 w / \%$. Therefore, the only possibility of distinguishing the areas with and without $\mathrm{Ag}$ is entirely manual, by observing each spectrum by itself and detecting the peak shapes. The peak shapes are different, since the sum peak of $\mathrm{Al}$ does not have a small peak at higher energies, while $\mathrm{Ag}$ also has a $\mathrm{L}_{\beta 1}$-peak $\left(\mathrm{Ag} \mathrm{L}_{\beta 1}=\right.$ $3.150 \mathrm{keV})$. An even bigger problem is that we cannot know for certain if there is small amount of $\mathrm{Ag}$ in the matrix, which is even more important than the concentration of the $\mathrm{Ag}$ in the inclusions.

\section{CONCLUSIONS}

The SEM has become a must-have in any research and development institution, while more and more operators are starting to use it. The SEM has evolved to probably the most widespread practical tool in the materials research community, with its imaging, elemental analytics, phase analyses, etc. From the described issues, just a tiny part of the possible problems are described. All of this can occur on any of the marketavailable machines. The "one button" machine for imaging and chemical analysis does not exist and the microscopist with a background knowledge of the materials, chemistry and physics is the only person who can and should be skilled enough to know them and be aware of the presented problems:

The "well-known limitation" of the equipment, like EDS mapping cannot show realistic results above $10,000 \times$ magnification, is true, but with some modifications, for example TEM prepared samples like lamella, even few nm particles could be observed and identified.

A rough surface cannot show the true chemical composition, while in some cases the x-rays of different elements penetrate to different depths.

The BSD different shading is not always connected to the different chemical composition (Z), but could be connected to the crystallography (lattice orientation).

Overlapping of the known element peaks for $\mathrm{K}_{\alpha 1}$ and $\mathrm{K}_{\beta 1}$, where even the latest software cannot distinguish the $\mathrm{Ti}$ and $\mathrm{V}$ in mapping, but could separate them in point and area analyses. 


\section{Č. DONIK: DO THE LATEST SCANNING ELECTRON MICROSCOPES WITH A VARIETY OF ANALYTICAL ...}

Overlapping of the sum peak of $\mathrm{Al}$ and $\mathrm{Ag}$ shows a higher amount of $\mathrm{Ag}$ where no $\mathrm{Ag}$ is diluted in the matrix.

\section{Acknowledgement}

The author acknowledges the financial support from the Slovenian Research Agency (research core funding No. P2-0132).

\section{REFERENCES}

${ }^{1}$ J. Goldstein, D.E . Newbury, D. C. Joy, C. E. Lyman, P. Echlin, E. Lifshin, L. C. Sawyer, J. R. Michael, Scanning electron microscopy and X-ray microanalysis, Springer Science, New York, 2003

${ }^{2}$ D. E. Newbury, N. W. M. Ritchie, Is scanning electron microscopy/ energy dispersive X-ray spectrometry (SEM/EDS) quantitative?, Scanning, 35 (2013) 141-168, doi:10.1002/sca.21041

${ }^{3}$ D. E. Newbury, N. W. M. Ritchie, Performing elemental microanalysis with high accuracy and high precision by scanning electron microscopy/silicon drift detector energy-dispersive X-ray spectrometry (SEM/SDD-EDS), J. Mater. Sci., 50 (2014) 493-518, doi:10.1007/s10853-014-8685-2

${ }^{4}$ C. Lang, M. Hiscock, Automated analysis of EDS maps, Microsc. Microanal., 22 (2016) 122-123, doi:10.1017/s143192761600146x

${ }^{5}$ N. W. M. Ritchie, D. E. Newbury, J. M. Davis, EDS measurements of X-ray intensity at WDS precision and accuracy using a silicon drift detector, Microsc. Microanal., 18 (2012) 892-904, doi:10.1017/ S1431927612001109

${ }^{6}$ T. Rönnhult, B. Brox, G. Fritze, The influence of surface topography on the x-ray intensity in electron microprobe analysis (EDS/WDS), Scanning, 9 (1987) 81-87, doi:10.1002/sca.4950090205

${ }^{7}$ S. M. Seddio, Standards-Based Quantitative EDS Mapping, Microsc. Microanal., 21 (2015) 2093-2094, doi:10.1017/s1431927615011241

${ }^{8}$ I. Paulin, M. Godec, Surface oxidation of heating resistors made from Kanthal AF: Increasing the lifetime of glow plugs, Vacuum, 138 (2017) 146-151, doi:10.1016/j.vacuum.2016.12.007.

${ }^{9}$ P. Wandrol, J. Matějková, A. Rek, High resolution imaging by means of backscattered electrons in the scanning electron microscope, Mater. Sci. Forum, 567-568 (2008) 313-316,doi:10.4028/ www.scientific.net/msf.567-568.313

${ }^{10}$ V. N. E. Robinson, Imaging with backscattered electrons in a scanning electron microscope, Scanning, 3 (1980) 15-26, doi:10.1002/sca.4950030103

${ }^{11}$ P. Kejzlar, M. Švec, E. Macajová, The usage of backscattered electrons in scanning electron microscopy, 14 (2014), 333-336

${ }^{12}$ L. Reimer, B. Volbert, Detector system for backscattered electrons by conversion to secondary electrons, Scanning, 2 (1979), 238-248

${ }^{13}$ D. Kaczmarek, Backscattered electrons topographic mode problems in the scanning electron microscope, Opt. Appl., 31 (2001), 649-658

${ }^{14}$ R. Garcia, F. A. Stevie, L. Giannuzzi, FIB sample preparation for in depth EDS analysis, Microsc. Microanal., 25 (2019), 914-915, doi:10.1017/s1431927619005300
${ }^{15}$ K. Hagita, T. Higuchi, H. Jinnai, Super-resolution for asymmetric resolution of FIB-SEM 3D imaging using AI with deep learning, Sci. Rep., 8 (2018) 5877, doi:10.1038/s41598-018-24330-1

${ }^{16}$ J.-H. Lee, K. Oh, A. Rajabi Abhari, H. L. Lee, Characterization of paper coating structure using FIB and FE-SEM Part 1. A new method for image analysis, Ind. Eng. Chem. Res., 57 (2018), doi:10.1021/acs.iecr.7b04673

${ }^{17}$ C. Li, G. Habler, L. C. Baldwin, R. Abart, An improved FIB sample preparation technique for site-specific plan-view specimens: A new cutting geometry, Ultramicroscopy. $184 \quad$ (2018) 310-317, doi:10.1016/j.ultramic.2017.09.011

${ }^{18}$ Casino, https://www.gel.usherbrooke.ca/casino/index.html, 14.11. 2019

${ }^{19}$ Z. J. Ding, H. M. Li, Application of Monte Carlo simulation to SEM image contrast of complex structures, Surf. Interface Anal., 37 (2005) 912-918, doi:10.1002/sia.2109

${ }^{20}$ P. J. Cumpson, M. P. Seah, Elastic scattering corrections in AES and XPS. 2. Estimating attenuation lengths and conditions required for their valid use in overlayer/substrate experiments, Surf. Interface Anal., 25 (1997), 430-446

${ }^{21}$ M. El Azzouzi, L. Khouchaf, A. Achahbar, Monte carlo study of the interaction volume changes by the beam skirt in Vp-Sem, Acta Phys. Pol. A., 132 (2017) 1393-1398, doi:10.12693/APhysPolA.132.1393

${ }^{22}$ R. Castaing, Application of electron probes to metallographic analysis, University of Paris, 1951

${ }^{23}$ P. J. Potts, A Handbook of Silicate Rock Analysis, Springer Netherlands, Dordrecht, 1987, doi:10.1007/978-94-015-3988-3

${ }^{24} \mathrm{Z}$. Wu, Standardless EDS analysis of bulk and thin specimens, J. Electron Microsc. Tech., 7 (1987) 323-329, doi:10.1002/jemt. 1060070412

${ }^{25}$ M. Miler, B. Mirtič, Accuracy and precision of EDS analysis for identification of metal-bearing minerals in polished and rough particle samples, Geologija, 56 (2013) 5-17, doi:10.5474/ geologija.2013.001

${ }^{26}$ I. Paulin, C. Donik, M. Jenko, Č. Donik, M. Jenko, Mechanisms of HF bonding in dry scrubber in aluminium electrolysis, Mater. Tehnol., 43 (2009) 189-193

${ }^{27}$ B. Šetina Batič, M. Jenko, Orientation-dependent ion beam sputtering at normal incidence conditions in FeSiAl alloy, J. Vac. Sci. Technol. A., 28 (2010) 741-744, doi:10.1116/1.3360924

${ }^{28}$ H. Kriaa, A. Guitton, N. Maloufi, Fundamental and experimental aspects of diffraction for characterizing dislocations by electron channeling

${ }^{29}$ M. Godec, B. Šetina Batič, D. Mandrino, A. Nagode, V. Leskovšek, S. D. Skapin, M. Jenko, Characterization of the carbides and the martensite phase in powder-metallurgy high-speed steel, Mater. Charact., 61 (2010) 452-458, doi:10.1016/j.matchar.2010.02.003

${ }^{30}$ I. Paulin, Stability of close-cell Al foams depending on the usage of different foaming agents, Mater. Tehnol.,49 (2015) 983-988

${ }^{31}$ I. Paulin, Synthesis and characterization of Al foams produced by powder metallurgy route using dolomite and titanium hydride as a foaming agents, Mater. Tehnol., 48 (2014) 943-947 